\title{
Functional genetic variants of the GATA4 gene promoter in acute myocardial infarction
}

\author{
JING CHEN $^{1 *}$, SHUAI WANG ${ }^{1 *}$, SHUCHAO PANG ${ }^{2,3}$, YINGHUA CUI $^{4}$, \\ BO YAN ${ }^{2,3,5}$ and ROBERT G. HAWLEY ${ }^{6}$
}

\author{
${ }^{1}$ Department of Medicine, Shandong University School of Medicine, Jinan, Shandong 250012; \\ ${ }^{2}$ Shandong Provincial Key Laboratory of Cardiac Disease Diagnosis and Treatment; ${ }^{3}$ Shandong Provincial Sino-US \\ Cooperation Research Center for Translational Medicine; ${ }^{4}$ Division of Cardiology; ${ }^{5}$ Center for Molecular Genetics of \\ Cardiovascular Diseases, Affiliated Hospital of Jining Medical University, Jining Medical University, \\ Jining, Shandong 272029, P.R. China; ${ }^{6}$ Department of Anatomy and Regenerative Biology, \\ The George Washington University, Washington, DC 20037, USA
}

Received June 4, 2018; Accepted January 25, 2019

DOI: $10.3892 / \mathrm{mmr} .2019 .9914$

\begin{abstract}
Coronary artery disease (CAD), including acute myocardial infarction (AMI), is a common complex disease; however, the genetic causes remain largely unknown. Recent epidemiological investigations indicated that the incidence of CAD in patients with congenital heart diseases is markedly higher than that observed in healthy controls. It was therefore hypothesized that the dysregulated expression of cardiac developmental genes may be involved in CAD development. GATA binding protein 4 (GATA4) serves essential roles in heart development and coronary vessel formation. In the present study, the GATA4 gene promoter was analyzed in patients with AMI $(n=395)$ and in ethnically-matched healthy controls $(n=397)$. A total of 14 DNA variants were identified, including two single-nucleotide polymorphisms. Three novel heterozygous DNA variants (g.31806C >T, g.31900G $>$ C and g.32241C $>\mathrm{T}$ ) were reported in three patients with AMI. These DNA variants significantly increased the activity of the GATA4 gene promoter. The electrophoretic mobility shift assay revealed that the DNA variant g.32241C $>$ T influenced
\end{abstract}

Correspondence to: $\mathrm{Dr}$ Bo Yan, Shandong Provincial Key Laboratory of Cardiac Disease Diagnosis and Treatment, Affiliated Hospital of Jining Medical University, Jining Medical University, 89 Guhuai Road, Jining, Shandong 272029, P.R. China

E-mail: yanbo@mail.jnmc.edu.cn

Professor Robert G. Hawley, Department of Anatomy and Regenerative Biology, The George Washington University, 2300 Eye Street, NW, Washington, DC 20037, USA

E-mail: rghawley@gwu.edu

${ }^{*}$ Contributed equally

Key words: acute myocardial infarction, GATA binding protein 4, gene expression, promoter, genetic variants the binding ability of transcription factors. Taken together, the DNA variants may alter GATA4 gene promoter activity and affect GATA4 levels, thus contributing to AMI development.

\section{Introduction}

Coronary artery disease (CAD), including acute myocardial infarction (AMI), is a common complex disease caused by atherosclerosis. Dysregulated lipid metabolism and inflammation serve critical roles in the initiation and progression of atherosclerosis $(1,2)$. A large number of genetic loci and variants have been identified in CAD and AMI, accounting for $\sim 10 \%$ of cases (3-5). To date, the genetic causes for CAD and AMI remain largely unknown. Previous epidemiological studies have indicated that the incidence of CAD in patients with congenital heart disease is markedly higher than that observed in the healthy population (6-8). Therefore, dysregulation of cardiac developmental genes may contribute to the pathogenesis of CAD.

The GATA transcription factor family, including GATA binding proteins 1-6 (GATA1-6), is involved in diverse physiological and pathological processes. GATA4-6 serve critical functions in the differentiation and proliferation of endodermand mesoderm-derived tissues (9-11). GATA4 is essential in the development of the heart, liver, pancreas, adrenal glands, gonads, gut, ovaries and testes (12). In experimental animals, GATA4 is essential in ventral morphogenesis and heart tube formation, as well as cardiomyocyte proliferation (13-15). Neonatal GATA4 gene inactivation causes severe and lethal systolic heart failure, indicating its autonomous function for physiological cardiomyocyte growth (16). GATA4 and its cofactor Friend of GATA (FOG) regulate coronary vascular development (17-19). In addition, deletion of GATA4 specifically from cardiomyocytes reduces myocardial capillary density (18). GATA4-null embryos exhibit an absent proepicardium and blocked epicardium formation $(20,21)$. Epicardium-derived cells populate the myocardial wall and develop into vascular smooth muscle cells, fibroblasts and 
endothelial cells (20). GATA4 also promotes myocardial regeneration in neonatal mice (22). In a recent report, GATA4 was reported to be involved in DNA damage response-induced inflammation and senescence, and GATA4 accumulation may result in aging and age-associated inflammation $(23,24)$.

GATA4 gene mutations have been implicated in familial and sporadic congenital heart diseases (25-27), and may cause neonatal and childhood-onset diabetes (28). Human GATA4 gene polymorphisms are also associated with plasma triglyceride levels $(29,30)$. In addition, GATA4 regulates cardiac morphogenesis and cardiovascular development in a dose-dependent manner $(31,32)$. Therefore, it was hypothesized that altered GATA levels may contribute to CAD and AMI through different pathways. In the present study, the GATA4 gene promoter was genetically and functionally analyzed in large cohorts of patients with AMI and ethnically-matched healthy controls.

\section{Materials and methods}

Study populations. Patients with AMI ( $\mathrm{n}=395 ; 295$ male and 100 female patients; median age, 61.48 years) were recruited between April 2014 and July 2016 from the Cardiac Care Unit, Division of Cardiology, Affiliated Hospital of Jining Medical University, Jining Medical University (Shandong, China). Patients with AMI were diagnosed according to clinical symptoms, electrocardiograms, elevated biochemical markers of myocardial necrosis or coronary angioplasty. Ethnically-matched healthy controls $(n=397 ; 210$ male and 187 female patients; median age, 50.39 years) were recruited from the same hospital during the same time period. Healthy controls with a familial history of CAD and congenital heart diseases were excluded from this study. The research was performed according to the principles of the Declaration of Helsinki, and the present study protocol was approved by the Human Ethics Committee of the Affiliated Hospital of Jining Medical University. Written informed consent was obtained from all of the participants.

Direct DNA sequencing. Peripheral leukocytes were collected from venous blood using the Human Leukocyte Isolation system (Haoyang Biological Products Technology Co., Ltd., Tianjin, China), according to the manufacturer's protocol. Genomic DNA was extracted with the QIAamp DNA Mini kit (Qiagen, Inc., Valencia, CA, USA). Two overlapped DNA fragments covering the GATA4 gene promoter region, 510 bp (between-961 and -451 bp) and 569 bp (between -502 and $+67 \mathrm{bp}$ ), were generated by polymerase chain reaction (PCR) with Taq DNA polymerase PCR master mix (Promega Corporation, Madison, WI, USA) and directly sequenced. The thermocycling conditions were as follows: $510 \mathrm{bp}$ fragment, 35 cycles of $94^{\circ} \mathrm{C}$ for $30 \mathrm{sec}, 56^{\circ} \mathrm{C}$ for $30 \mathrm{sec}$ and $72^{\circ} \mathrm{C}$ for $45 \mathrm{sec} ; 569 \mathrm{bp}$ fragment, 35 cycles of $94^{\circ} \mathrm{C}$ for $30 \mathrm{sec}, 62^{\circ} \mathrm{C}$ for $30 \mathrm{sec}$ and $72^{\circ} \mathrm{C}$ for $45 \mathrm{sec}$. PCR primers were designed using the human GATA4 genomic sequence (National Center for Biotechnology Information GenBank accession no. NG_008177.2; https://www.ncbi. nlm.nih.gov/genbank/; Table I). Bidirectional sequencing of PCR products was performed on a 3500XL genetic analyzer (Thermo Fisher Scientific, Inc., Waltham, MA, USA) by
Sangon Biotech Co., Ltd. (Shanghai, China). DNA sequences were then compared with the wild-type GATA4 gene promoter using the DNAMAN program (version 5.2.2; Lynnon BioSoft, Quebec, Canada), and DNA variants were identified. The DNA variants in the GATA4 gene promoter were first analyzed using JASPAR program (jaspar.genereg.net) to predict their effects on binding sites for transcription factors, which were further experimentally confirmed.

Functional analysis of the GATA4 gene promoter by dual-luciferase reporter assay. Wild-type and variant GATA4 gene promoters (971 bp, between $-932 \mathrm{bp}$ and $+39 \mathrm{bp}$ ) were generated by PCR and inserted into the SacI and HindIII sites of a luciferase reporter vector (pGL3-basic, Promega Corporation), in order to generate expression constructs. The PCR primers are presented in Table I. 293 [CRL-1573; American Type Culture Collection (ATCC), Manassas, VA, USA] and H9c2 cells (rat cardiomyocyte line; CRL-1446; ATCC) were transiently transfected with the designated constructs. Briefly, on the day prior to transfection the cells were seeded in 6-well plates at 40-50 and 50-60\% confluence for 293 cells and H9c2 cells, respectively. Designated expression constructs $(1.0 \mu \mathrm{g})$ and Lipofectamine ${ }^{\circledR}(3.0 \mu \mathrm{l} ;$ Invitrogen; Thermo Fisher Scientific, Inc.) in $500 \mathrm{ml}$ serum-free medium were used to transfect the cells in each well. The vector expressing Renilla luciferase (pRL-TK; 25 ng, Promega Corporation) was used as an internal control for transfection efficiency. A total of $48 \mathrm{~h}$ post-transfection, luciferase activity was examined using the Promega Dual-Luciferase ${ }^{\circledR}$ Reporter Assay system on a Promega Glomax 20/20 luminometer (both Promega Corporation). GATA4 gene promoter activity was expressed as the ratio of luciferase activity over Renilla luciferase activity. The activity of the wild-type GATA4 gene promoter was set as $100 \%$.

Nuclear extract preparation and electrophoretic mobility shift assay (EMSA). Nuclear extracts from 293 and H9c2 cells were prepared using NE-PER ${ }^{\circledR}$ Nuclear and Cytoplasmic Extraction Reagent kit (Thermo Fisher Scientific, Inc.) and protein concentrations were determined using the Bradford protein assay. EMSA was conducted using the LightShift ${ }^{\circledR}$ Chemiluminescent EMSA kit (Thermo Fisher Scientific, Inc.). Biotinylated double-stranded oligonucleotides (30 bp) containing the DNA variants identified in AMI patients were used as probes. DNA-protein binding reactions were conducted for $20 \mathrm{~min}$ at room temperature with equal amounts of probes $(0.2 \mathrm{pM})$ and nuclear extracts $(3.0 \mu \mathrm{g})$. Subsequently, the reactions were separated on a $6 \%$ polyacrylamide gel and transferred onto a nylon membrane (Thermo Fisher Scientific, Inc.). The oligonucleotides were cross-linked to the membrane using the UV Stratalinker 1800 (Stratagene; Agilent Technologies, Inc., Santa Clara, CA, USA) and were detected by chemiluminescence using the LightShift ${ }^{\circledR}$ Chemiluminescent EMSA kit (Thermo Fisher Scientific, Inc.).

Statistical analysis. All transfection experiments were repeated three times independently, in triplicate. Transfection results are expressed as the means \pm standard error of the mean and were analyzed using two-way analysis of variance followed by Dunnett's test. The frequency of DNA variants was compared 
Table I. PCR primers for the GATA4 gene promoter.

\begin{tabular}{|c|c|c|c|c|}
\hline PCR primers & Sequence & Location & Position & Product size (bp) \\
\hline \multicolumn{5}{|l|}{ Sequencing } \\
\hline GATA4-F1 & 5'-AAGTTTAACCGAAAGCGTGAG-3' & 31,292 & -961 & 510 \\
\hline GATA4-R1 & 5'-CCAGACTGCCTCCTAAAATCA-3' & 31,781 & -451 & \\
\hline GATA4-F2 & 5'-GGCAAAAGGGAGGCTTCGGTC-3' & 31,731 & -502 & 569 \\
\hline GATA4-R2 & 5'-CCGCCTCCAAGTCCCCAGCTC-3' & 32,299 & +67 & \\
\hline \multicolumn{5}{|l|}{ Function } \\
\hline GATA4-F & 5'-(SacI)-GCCGGCTGTTATCTGGGGCTGAAGG-3' & 31,270 & -932 & 971 \\
\hline GATA4-R & 5'-(HindIII)-GGGTCCCCGGCCCAGCAACT-3' & 32,271 & +39 & \\
\hline
\end{tabular}

PCR primers were designed based on the genomic DNA sequence of the GATA4 gene (NG_008177.2). The transcription start site is at the position of 32,233 (+1). F, forward; GATA4, GATA binding protein 4; PCR, polymerase chain reaction; R, reverse.

using SPSS v13.0 software (SPSS, Inc., Chicago, IL, USA). $\mathrm{P}<0.05$ was considered to indicate a statistically significant difference.

\section{Results}

DNA variants in the GATA4 gene promoter. A total of 14 DNA variants were identified in the GATA4 gene promoter, including two single-nucleotide polymorphisms (SNPs). The frequency and locations of the DNA variants and SNPs are presented in Fig. 1 and Table II. Three novel heterozygous DNA variants (g.31806C $>$ T, g.31900G $>C$ and $32241 \mathrm{C}>\mathrm{T}$ ) were only identified in three patients with AMI (Fig. 2A). Eight novel heterozygous DNA variants (g.31403G $>$ T, g.31492T $>$ A, g.31566G $>C$, g.31567A $>$ G, g.31715C $>A$, g.31730A $>$ G, g.32171 A $>$ G and g.32190C $>$ T) were only found in healthy controls (Fig. 2B). One insertion, heterozygous DNA variant (g.31979_31980InsG) and two SNPs [g.31360T>C (rs372004083) and g.31437C >A (rs769262495)] were reported in patients with AMI and controls with similar frequencies $(\mathrm{P}>0.05)$, the sequencing chromatograms of which were not shown.

DNA variants affect the binding of transcription factors. The GATA4 gene promoter was first analyzed using JASPAR program (jaspar.genereg.net/). The JASPAR program predicts whether DNA variants alter the putative binding sites for transcription factors, and these predictions require experimental confirmation. For the DNA variants identified in patients with AMI, the DNA variant (g.31806C $>$ T) abolished a putative binding site for early growth response protein 1 . The DNA variant (g.31900G $>$ C) disrupted a binding site for zinc finger protein $354 \mathrm{C}$, and the DNA variant (g.32241C $>\mathrm{T})$ altered a binding site for the transcription factor AP- $2 \alpha$. For the DNA variants only identified in controls, the DNA variants (g.31403G $>$ T, g.31567A $>$ G, g.31715C $>A$, g.32171 A $>$ G and g.32190C $>$ T) did not affect the binding of transcription factors. The DNA variant (g.31492T >A) altered a binding site for myeloid zinc finger protein 1 (MZF1). The DNA variant (g.31566G $>$ C) disrupted a binding site for helicase-like transcription factor and the DNA variant (g.31730A $>$ G) disrupted a binding site for signal transducer and activator

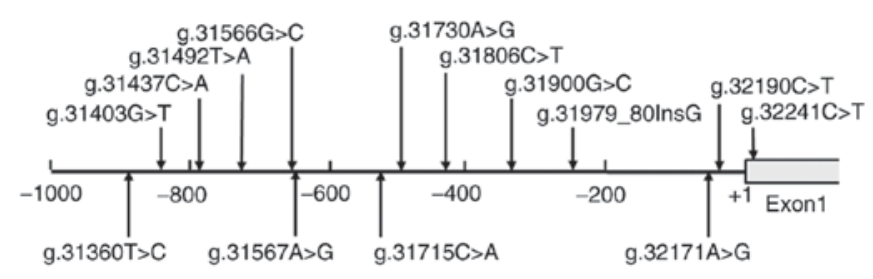

Figure 1. Locations of the DNA variants in the GATA4 gene promoter. Numbers represent the genomic sequences of the human GATA4 gene (National Center for Biotechnology Information GenBank accession no. NG_008177.2). The transcription start site is at position 32,233 (+1) in the first exon. GATA4, GATA binding protein 4.

of transcription 3. For the DNA variants detected in patients with AMI and controls, the DNA variant g.31360T $>$ C (rs372004083) altered a binding site for homeodomain transcription factor Distal-less 6. Furthermore, the DNA variant g.31437C >A (rs769262495) created a binding site for MZF1. Finally, the DNA variant (g.31979_31980insG) created a binding site for zinc finger protein 704 .

GATA4 gene promoter activity. The expression constructs containing wild-type and variant GATA4 gene promoters: pGL3-WT (wild-type), pGL3-31715A, pGL3-31730G, pGL3-31806T, pGL3-31900C and pGL3-32241T, were transfected into 293 and H9c2 cells. The dual-luciferase activities were measured and relative activity of wild-type and variant GATA4 gene promoters were examined. Three DNA variants ( g. 31806C $>$ T, g.31900G $>$ C and 32241C $>$ T) identified only in patients with AMI were assessed for their effects on GATA4 gene promoter activity. In addition, two of the eight DNA variants found only in controls were tested as negative controls for transfection. The transcriptional activity of pGL3-WT containing wild-type GATA4 gene promoter was set as $100 \%$. The transcriptional activity of variant GATA4 gene promoters was compared to that of pGL3-WT.

293 cells were used in this study, as the cell line has been widely used in transient transfection experiments. The results in 293 cells are shown in Fig. 3A. Compared with pGL3-WT, the transcriptional activity of empty pGL3-basic containing no promoter was close to zero, confirming that transfection 
Table II. DNA variants within the GATA binding protein 4 gene promoter in patients with AMI and controls.

\begin{tabular}{|c|c|c|c|c|c|}
\hline DNA variants & Genotype & Location $^{\mathrm{a}}$ (bp) & Controls $(n=397)$ & AMI $(n=395)$ & P-value \\
\hline g.31360T >C (rs372004083) & $\mathrm{TC}$ & -837 & 1 & 1 & 1.000 \\
\hline g. $31403 \mathrm{G}>\mathrm{T}$ & GT & -830 & 1 & 0 & - \\
\hline g.31437C>A (rs769262495) & $\mathrm{CA}$ & -796 & 4 & 1 & 0.373 \\
\hline g. $31492 \mathrm{~T}>\mathrm{A}$ & TA & -741 & 1 & 0 & - \\
\hline g.31566G >C & $\mathrm{GC}$ & -667 & 1 & 0 & - \\
\hline g. $31567 \mathrm{~A}>\mathrm{G}$ & $\mathrm{AG}$ & -666 & 1 & 0 & - \\
\hline g. $31715 \mathrm{C}>\mathrm{A}$ & $\mathrm{CA}$ & -518 & 1 & 0 & - \\
\hline g. $31730 \mathrm{~A}>\mathrm{G}$ & $\mathrm{AG}$ & -503 & 1 & 0 & - \\
\hline g.31806C $>\mathrm{T}$ & CT & -427 & 0 & 1 & - \\
\hline g.31900G >C & $\mathrm{GC}$ & -333 & 0 & 1 & - \\
\hline g.31979_31980InsG & $-/ G$ & -256 & 8 & 2 & 0.107 \\
\hline g.32171A $>\mathrm{G}$ & $\mathrm{AG}$ & -62 & 1 & 0 & - \\
\hline g.32190C > T & CT & +43 & 1 & 0 & - \\
\hline g. $32241 \mathrm{C}>\mathrm{T}$ & $\mathrm{CT}$ & +9 & 0 & 1 & - \\
\hline
\end{tabular}

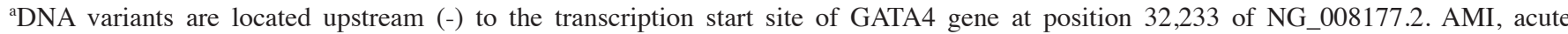
myocardial infarction.
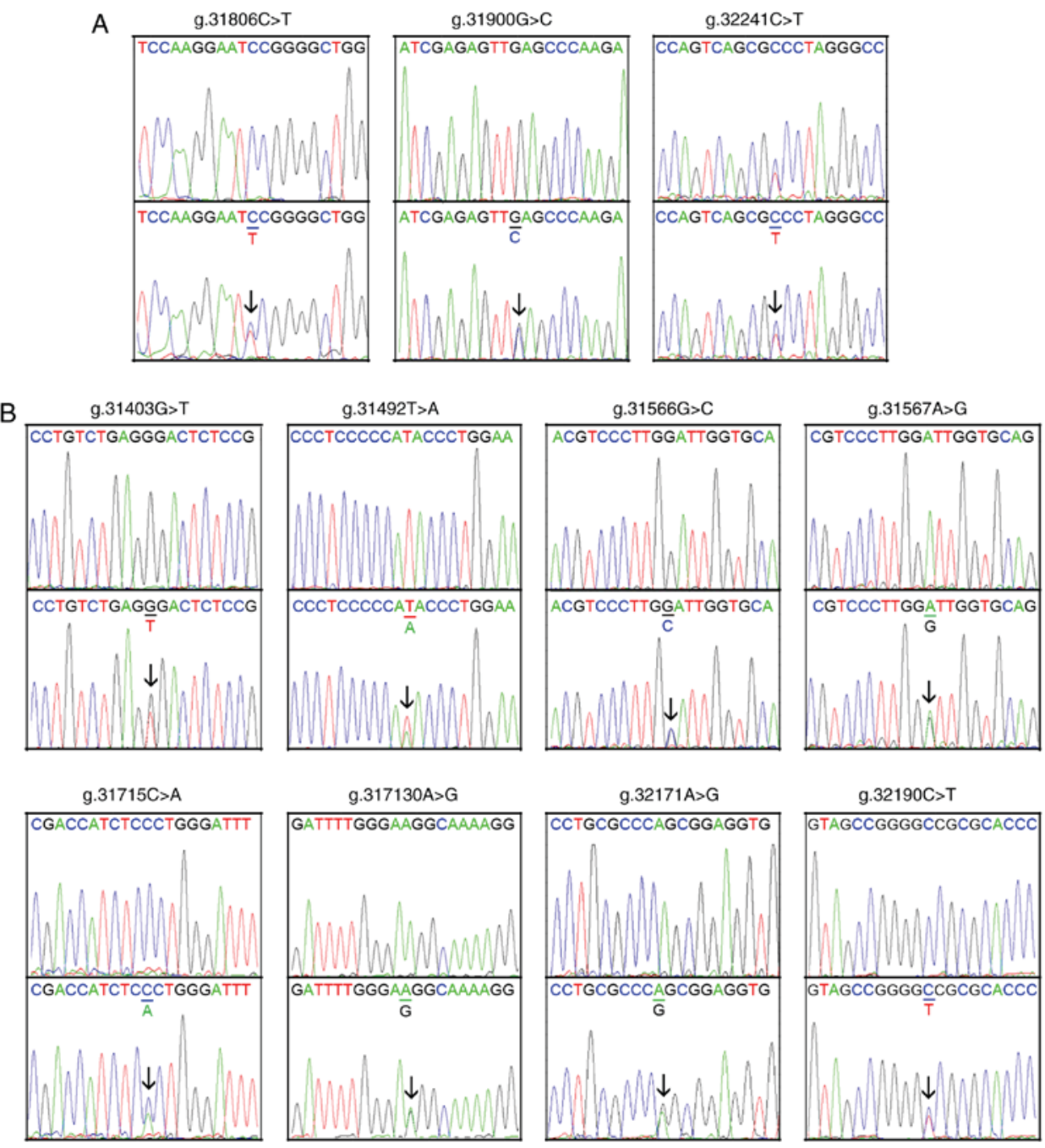

Figure 2. Sequencing chromatograms of the GATA binding protein 4 gene promoter DNA variants. (A) DNA variants identified in patients with AMI. (B) DNA variants identified in the healthy controls. The sequence orientations of the DNA variants are forward. The top panels represent the wild-type and the bottom panels represent the heterozygous variants, which are marked with arrows. AMI, acute myocardial infarction. 

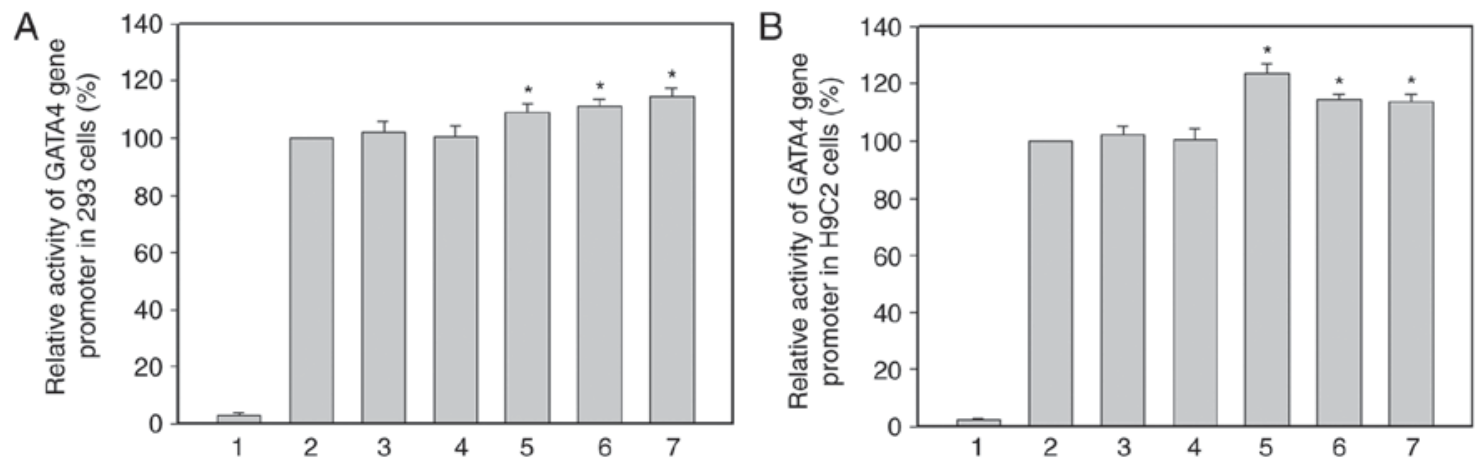

Figure 3. Relative transcriptional activity of wild-type and variant GATA4 gene promoters. The transcriptional activity of the WT GATA4 gene promoter was set as $100 \%$. Empty pGL3-basic, containing no promoter, was used as a blank control for transfection. (A) Relative activity of the WT and variant GATA4 gene promoters in 293 cells. (B) Relative activities of the WT and variant GATA4 gene promoters in H9c2 cells. 1, pGL3-basic; 2, pGL3-WT; 3, pGL3-31715A; 4, pGL3-31730G; 5, pGL3-31806T; 6, pGL3-31900C; 7, pGL3-32241T. *P<0.001 compared with pGL3-WT. GATA4, GATA transcription factor 4 ; WT, wild-type.

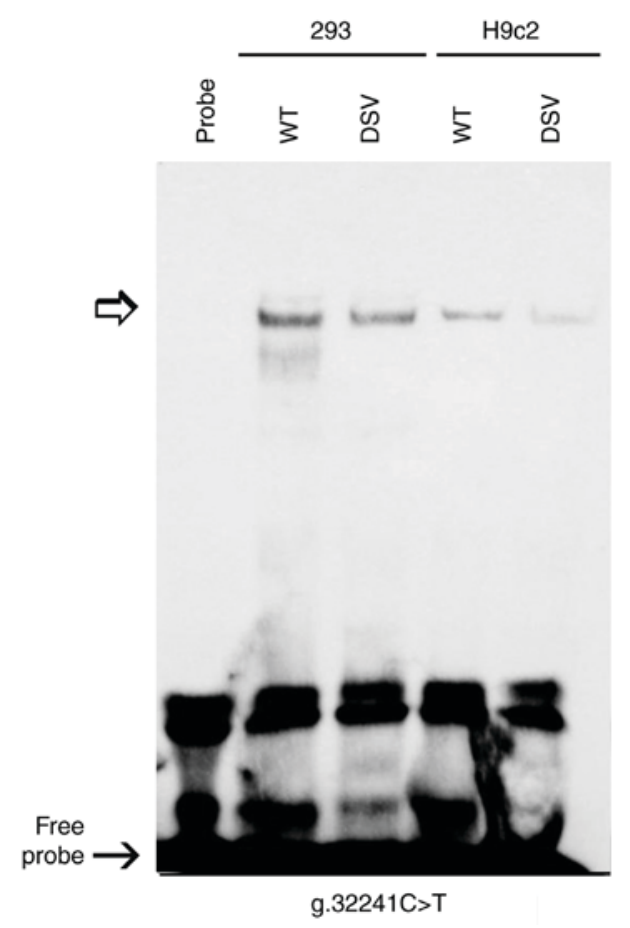

Figure 4. Electrophoretic mobility shift assay of biotin-labeled oligonucleotides containing the DNA variant g.32241C > T with nuclear extracts from 293 and H9c2 cells. The free probe was marked with an arrow. The affected binding of an unknown transcription factor was marked with an open arrow. DSV, DNA sequence variant; WT, wild-type.

with the wild-type and variant GATA4 gene promoters was successful. In 293 cells, the DNA variants (g.31806C $>$ T, g.31900G $>$ C and $32241 \mathrm{C}>\mathrm{T}$ ) identified only in patients with AMI significantly increased transcriptional activity of the GATA4 gene promoter $(\mathrm{P}<0.001)$. Conversely, the DNA variants $(31715 \mathrm{C}>\mathrm{A}$ and $31730 \mathrm{~A}>\mathrm{G})$ only identified in controls did not significantly affect activity of the GATA4 gene promoter (P>0.05; Fig. 3A).

Since human cardiomyocyte cell lines are currently not available, the $\mathrm{H} 9 \mathrm{c} 2$ rat cardiomyocyte cell line was used. Similar to in 293 cells, the transcriptional activity of empty pGL3-basic containing no promoter was close to zero in $\mathrm{H} 9 \mathrm{c} 2$ cells, thus indicating successful transfection. In $\mathrm{H} 9 \mathrm{c} 2$ cells, the DNA variants (g.31806C $>$ T, g.31900G $>C$ and $32241 \mathrm{C}>\mathrm{T}$ ) identified only in patients with AMI significantly increased activity of the GATA4 gene promoter $(\mathrm{P}<0.001)$, which was consistent with the results observed in 293 cells. The DNA variants $(31715 \mathrm{C}>\mathrm{A}$ and $31730 \mathrm{~A}>\mathrm{G})$ observed only in the controls did not significantly alter the activity of the GATA4 gene promoter $(\mathrm{P}>0.05)$. Collectively, these findings indicated that the effects of the DNA variants were not tissue-specific (Fig. 3B).

Transcription factor binding as determined by EMSA. To investigate whether the DNA variants affected the binding of transcription factors, EMSA was performed with wild-type or variant oligonucleotides, including the DNA variants g.31806C >T [5'-GAACCTCCAAGGAAT(C/T)CGGGGC TGGGAGGA-3')], g.31900G>C [5'-ACAAGATCGAGAGTT (G/C)AGCCCAAGAGGTCA-3'] and g.32241C>T [5'-CAC AGCGAACCCAAT(C/A)GACCTCCGGCTGGG-3']. The DNA variant g.32241C $>$ T markedly reduced the binding of an unknown transcription factor in 293 and H9c2 cells (Fig. 4). The affected transcription factor, which acted as a transcriptional activator, requires further identification. The effects of the other two DNA variants (g.31806C >T and g.31900G >C) on the binding of transcription factors were not detected, likely due to the sensitivity limit of EMSA experiments. Therefore, these DNA variants may affect the binding of transcription factors, altering the activity of the GATA4 gene promoter.

\section{Discussion}

Human studies and animal experiments have indicated that GATA4 is a critical regulator in heart development, as well as cardiac function. Insufficient or excessive GATA4 not only cause congenital heart diseases, but are also involved in the development of late-onset heart disease. In our previous study, five functional DNA variants in the GATA4 gene promoter were identified in patients with congenital heart diseases (33). In the present study, the GATA4 gene promoter was further genetically and functionally analyzed in a large cohort of patients with AMI and healthy controls. The results revealed that three novel heterozygous DNA variants $(\mathrm{g} .31806 \mathrm{C}>\mathrm{T}$, g. $31900 \mathrm{G}>\mathrm{C}$ and $32241 \mathrm{C}>\mathrm{T}$ ) were found in three patients 
with AMI. In 293 cells and H9c2 cardiomyocytes, these DNA variants significantly increased the transcriptional activity of the GATA4 gene promoter. Furthermore, EMSA experiments revealed that the DNA variant g.32241C $>$ T affected the binding of transcription factors. The effects of the other two DNA variants (g.31806C $>$ T and g.31900G $>$ C) were not detected by EMSA, likely due to EMSA sensitivity. Collectively, the frequency of the DNA variants was $0.76 \%$ (3 out 395), thus suggesting that the GATA4 gene promoter DNA sequence variants were rare. Therefore, these DNA variants may contribute to AMI as a rare risk factor.

The human GATA4 gene has been localized to 8p23.1-p22 $(34,35)$. The GATA4 gene is regulated in a modular manner to control distinct temporal and spatial expression patterns (12). The human GATA4 gene promoter is a typical TATA-less promoter with conserved GC-boxes and an E-box. A GATA motif at $\sim 1.0 \mathrm{~kb}$ upstream of the transcription start site indicates that GATA4 gene expression may be autoregulated (36). In addition, the GATA4 gene is regulated by Forkhead factors, subunits of SWI/SNF complex, bone morphogenetic protein signaling molecules and microRNAs (miRs) (37-41). In a previous study, GATA4 gene transcript levels were revealed to be significantly higher in the peripheral blood mononuclear cells of patients with severe stable CAD (42). This study provided further supportive evidence.

During cardiac development, numerous GATA4-interacting proteins, including transcriptional activators and repressors, and downstream targets of GATA4 have been reported. GATA4 serves a crucial role in cardiogenesis and $\alpha$-cardiomyocyte function by regulating cardiac-associated genes, including troponin $\mathrm{C}$, cardiac-myosin heavy chain and brain-type natriuretic factor genes (43-46). GATA4, together with the cardiac specific factors T-box transcription factor 5 (TBX5) and NK2 homeobox 5 (NKX2.5), directly regulates the cardiac-specific expression of the connexin 40 gene (47). GATA4 interacts and directly induces the expression of cyclin D2 and cyclin-dependent kinase 4 genes, which are required for cardiomyocyte proliferation (48-50). Furthermore, GATA4 specifically cooperates with NKX2.5 to activate atrial natriuretic factor (ANF) and other cardiac genes $(43,51)$. GATA4 also activates the NKX2-5 gene via a novel upstream enhancer (52). GATA4 interacts with GATA5 and GATA6 in endocardial cushion formation and outflow tract morphogenesis (53). Interactions between GATA4 and GATA6 with TBX5 serve a unique role in normal cardiac morphogenesis $(54,55)$. In addition, the complex interdependence of GATA4, NKX2-5 and TBX 5 controls cardiac gene expression in cardiac morphogenesis (56). GATA4 physically interacts with heart and neural crest derivatives expressed 2, a basic helix-loop-helix transcription factor, to synergistically activate cardiac gene expression, including ANF, the B-type natriuretic peptide gene and the $\alpha$-myosin heavy chain gene $(57,58)$. Therefore, altered levels of GATA4 may interfere with the cardiac gene regulatory network, resulting in cardiomyocyte dysfunction.

GATA4 has a role in cardiac angiogenesis and promotes pressure overload-induced angiogenesis. GATA4 induces the angiogenic factor, vascular endothelial growth factor A, by directly binding to its promoter and enhancing its transcription (18). GATA4-mediated miR-144/451 cluster exerts synergistic effects in protecting against cardiomyocyte death (59). GATA4 and the cardiac transcription factors, nuclear factor of activated T-cells, myocyte enhancer factor-2 and serum response factor, synergistically activate the expression of the endothelial-specific endothelin-1 gene (11,60-63). Endothelin-1 causes endothelial dysfunction and inflammation, contributing to atherosclerotic plaque formation (64). FOG-2 is also essential for cardiac morphogenesis and coronary vessel development in the epicardium (19). Therefore, elevated GATA4 may contribute to AMI through its function in coronary artery formation.

In conclusion, the GATA4 gene promoter was genetically and functionally analyzed. The DNA variants identified in patients with AMI significantly increased GATA4 gene promoter activity. EMSA revealed that the DNA variants affected the binding of transcription factors, which may modify GATA4 gene promoter activity to subsequently alter its expression levels. Therefore, DNA variants in the GATA4 gene promoter may contribute to AMI as a rare risk factor. The data from the present study may provide a genetic basis for designing potential precision therapy for patients with AMI.

\section{Acknowledgements}

Not applicable.

\section{Funding}

The present study was supported by the National Natural Science Foundation of China (grant nos. 81370271, 81400291 and 81670341) and the Taishan Scholar Program (grant no. TSHW201502063), Shandong, China.

\section{Availability of data and materials}

The datasets used and/or analyzed during the current study are available from the corresponding author on reasonable request.

\section{Authors' contributions}

BY and RGH designed the present study. JC, SW and YC collected the samples and performed the experiments. SP and YC analyzed the data. JC and SW wrote the paper. BY and RGH reviewed and edited the manuscript. All authors read and approved the final manuscript.

\section{Ethics approval and consent to participate}

The present study was approved by the Human Ethics Committee of the Affiliated Hospital of Jining Medical University. Written informed consent was obtained from all participants.

\section{Patient consent for publication}

Not applicable.

\section{Competing interests}

The authors declare that they have no competing interests. 


\section{References}

1. Connelly MA, Shalaurova I and Otvos JD: High-density lipoprotein and inflammation in cardiovascular disease. Transl Res 173 7-18, 2016

2. Shapiro MD and Fazio S: From lipids to inflammation: New approaches to reducing atherosclerotic risk. Circ Res 118: 732-749, 2016.

3. Assimes TL and Roberts R: Genetics: Implications for prevention and management of coronary artery disease. J Am Coll Cardiol 68: 2797-2818, 2016

4. Björkegren JL, Kovacic JC, Dudley JT and Schadt EE: Genome-wide significant loci: How important are they? Systems genetics to understand heritability of coronary artery disease and other common complex disorders. J Am Coll Cardiol 65 830-845, 2015

5. McPherson R and Tybjaerg-Hansen A: Genetics of coronary artery disease. Circ Res 118: 564-578, 2016.

6. Fedchenko M, Mandalenakis Z, Rosengren A, Lappas G, Eriksson P, Skoglund K and Dellborg M: Ischemic heart disease in children and young adults with congenital heart disease in Sweden. Int J Cardiol 248: 143-148, 2017.

7. Olsen M, Marino B, Kaltman J, Laursen H, Jakobsen L, Mahle W, Pearson G and Madsen N: Myocardial infarction in adults with congenital heart disease. Am J Cardiol 120: 2272-2277, 2017.

8. Tutarel O, Kempny A, Alonso-Gonzalez R, Jabbour R, Li W, Uebing A, Dimopoulos K, Swan L, Gatzoulis MA and Diller GP: Congenital heart disease beyond the age of 60: Emergence of a new population with high resource utilization, high morbidity, and high mortality. Eur Heart J 35: 725-732, 2014.

9. Lentjes MH, Niessen HE, Akiyama Y, de Bruïne AP, Melotte V and van Engeland M: The emerging role of GATA transcription factors in development and disease. Expert Rev Mol Med 18: e3, 2016.

10. Peterkin T, Gibson A, Loose $M$ and Patient R: The roles of GATA-4, -5 and -6 in vertebrate heart development. Semin Cell Dev Biol 16: 83-94, 2005.

11. Pikkarainen S, Tokola H, Kerkelä R and Ruskoaho H: GATA transcription factors in the developing and adult heart. Cardiovasc Res 63: 196-207, 2004.

12. Burch JB: Regulation of GATA gene expression during vertebrate development. Semin Cell Dev Biol 16: 71-81, 2005.

13. Kuo CT, Morrisey EE, Anandappa R, Sigrist K, Lu MM, Parmacek MS, Soudais C and Leiden JM: GATA4 transcription factor is required for ventral morphogenesis and heart tube formation. Genes Dev 11: 1048-1060, 1997.

14. Molkentin JD, Lin Q, Duncan SA and Olson EN: Requirement of the transcription factor GATA4 for heart tube formation and ventral morphogenesis. Genes Dev 11: 1061-1072, 1997.

15. Zeisberg EM, Ma Q, Juraszek AL, Moses K, Schwartz RJ, Izumo S and Pu WT: Morphogenesis of the right ventricle requires myocardial expression of Gata4. J Clin Invest 115: 1522-1531, 2005.

16. Prendiville TW, Guo H, Lin Z, Zhou P, Stevens SM, He A, VanDusen N, Chen J, Zhong L, Wang DZ, et al: Novel roles of GATA4/6 in the postnatal heart identified through temporally controlled, cardiomyocyte-specific gene inactivation by Adeno-associated virus delivery of Cre recombinase. PLoS One 10: e0128105, 2015.

17. Crispino JD, Lodish MB, Thurberg BL, Litovsky SH, Collins T, Molkentin JD and Orkin SH: Proper coronary vascular development and heart morphogenesis depend on interaction of GATA-4 with FOG cofactors. Genes Dev 15: 839-844, 2001.

18. Heineke J, Auger-Messier M, Xu J, Oka T, Sargent MA, York A, Klevitsky R, Vaikunth S, Duncan SA, Aronow BJ, et al: Cardiomyocyte GATA4 functions as a stress-responsive regulator of angiogenesis in the murine heart. J Clin Invest 117: 3198-3210, 2007

19. Tevosian SG,Deconinck AE, Tanaka M, Schinke M, Litovsky SH, Izumo S, Fujiwara Y and Orkin SH: FOG-2, a cofactor for GATA transcription factors, is essential for heart morphogenesis and development of coronary vessels from epicardium. Cell 101: 729-739, 2000

20. Schlueter J and Brand T: Epicardial progenitor cells in cardiac development and regeneration. J Cardiovasc Transl Res 5: 641-653, 2012

21. Watt AJ, Battle MA, Li J and Duncan SA: GATA4 is essential for formation of the proepicardium and regulates cardiogenesis. Proc Natl Acad Sci USA 101: 12573-12578, 2004.
22. Malek Mohammadi M, Kattih B, Grund A, Froese N, Korf-Klingebiel M, Gigina A, Schrameck U, Rudat C, Liang Q, Kispert A, et al: The transcription factor GATA4 promotes myocardial regeneration in neonatal mice. EMBO Mol Med 9: 265-279, 2017.

23. Kang C, Xu Q, Martin TD, Li MZ, Demaria M, Aron L, Lu T, Yankner BA, Campisi J and Elledge SJ: The DNA damage response induces inflammation and senescence by inhibiting autophagy of GATA4. Science 349: aaa5612, 2015.

24. Mazzucco AE, Smogorzewska A, Kang C, Luo J, Schlabach MR, $\mathrm{Xu} \mathrm{Q}$, Patel R and Elledge SJ: Genetic interrogation of replicative senescence uncovers a dual role for USP28 in coordinating the p53 and GATA4 branches of the senescence program. Genes Dev 31: 1933-1938, 2017.

25. Garg V, Kathiriya IS, Barnes R, Schluterman MK, King IN, Butler CA, Rothrock CR, Eapen RS, Hirayama-Yamada K, Joo K, et al: GATA4 mutations cause human congenital heart defects and reveal an interaction with TBX5. Nature 424: 443-447, 2003

26. Rajagopal SK, Ma Q, Obler D, Shen J, Manichaikul A, Tomita-Mitchell A, Boardman K, Briggs C, Garg V, Srivastava D, et al: Spectrum of heart disease associated with murine and human GATA4 mutation. J Mol Cell Cardiol 43: 677-685, 2007

27. Su W, Zhu P, Wang R, Wu Q, Wang M, Zhang X, Mei L, Tang J, Kumar M, Wang X, et al: Congenital heart diseases and their association with the variant distribution features on susceptibility genes. Clin Genet 91: 349-354, 2017.

28. Shaw-Smith C, De Franco E, Lango Allen H, Batlle M, Flanagan SE, Borowiec M, Taplin CE, van Alfen-van der Velden J, Cruz-Rojo J, Perez de Nanclares G, et al: GATA4 mutations are a cause of neonatal and childhood-onset diabetes. Diabetes 63: 2888-2894, 2014.

29. Lamina C, Coassin S, Illig T and Kronenberg F: Look beyond one's own nose: Combination of information from publicly available sources reveals an association of GATA4 polymorphisms with plasma triglycerides. Atherosclerosis 219: 698-703, 2011.

30. Muiya NP, Wakil SM, Tahir AI, Hagos S, Najai M, Gueco D, Al-Tassan N, Andres E, Mazher N, Meyer BF and Dzimiri N: A study of the role of GATA4 polymorphism in cardiovascular metabolic disorders. Hum Genomics 7: 25, 2013.

31. Xin M, Davis CA, Molkentin JD, Lien CL, Duncan SA, Richardson JA and Olson EN: A threshold of GATA4 and GATA6 expression is required for cardiovascular development. Proc Natl Acad Sci USA 103: 11189-11194, 2006.

32. Pu WT, Ishiwata T, Juraszek AL, Ma Q and Izumo S: GATA4 is a dosage-sensitive regulator of cardiac morphogenesis. Dev Biol 275: 235-244, 2004.

33. Wu G, Shan J, Pang S, Wei X, Zhang H and Yan B: Genetic analysis of the promoter region of the GATA4 gene in patients with ventricular septal defects. Transl Res 159: 376-382, 2012.

34. Huang WY, Heng HH and Liew CC: Assignment of the human GATA4 gene to 8p23.1->p22 using fluorescence in situ hybridization analysis. Cytogenet Cell Genet 72: 217-218, 1996.

35. White RA, Dowler LL, Pasztor LM, Gatson LL, Adkison LR, Angeloni SV and Wilson DB: Assignment of the transcription factor GATA4 gene to human chromosome 8 and mouse chromosome 14: Gata4 is a candidate gene for Ds (disorganization). Genomics 27: 20-26, 1995.

36. Ohara Y, Atarashi T, Ishibashi T, Ohashi-Kobayashi A and Maeda M: GATA-4 gene organization and analysis of its promoter. Biol Pharm Bull 29: 410-419, 2006.

37. Liang W, Guo J, Li J, Bai C and Dong Y: Downregulation of miR-122 attenuates hypoxia/reoxygenation (H/R)-induced myocardial cell apoptosis by upregulating GATA-4. Biochem Biophys Res Commun 478: 1416-1422, 2016.

38. Mehta G, Kumarasamy S, Wu J, Walsh A, Liu L, Williams K, Joe B and de la Serna IL: MITF interacts with the SWI/SNF subunit, BRG1, to promote GATA4 expression in cardiac hypertrophy. J Mol Cell Cardiol 88: 101-110, 2015.

39. Rojas A, De Val S, Heidt AB, Xu SM, Bristow J and Black BL: Gata4 expression in lateral mesoderm is downstream of BMP4 and is activated directly by Forkhead and GATA transcription factors through a distal enhancer element. Development 132: 3405-3417, 2005.

40. Si L, Shi J, Gao W, Zheng M, Liu L, Zhu J and Tian J: Smad4 mediated BMP2 signal is essential for the regulation of GATA4 and $\mathrm{Nkx} 2.5$ by affecting the histone $\mathrm{H} 3$ acetylation in $\mathrm{H} 9 \mathrm{c} 2$ cells. Biochem Biophys Res Commun 450: 81-86, 2014. 
41. Zhou C, Cui Q, Su G, Guo X, Liu X and Zhang J: MicroRNA-208b alleviates post-infarction myocardial fibrosis in a rat model by inhibiting GATA4. Med Sci Monit 22: 1808-1816, 2016.

42. Kontaraki JE, Kochiadakis GE, Marketou ME, Chlouverakis G, Igoumenidis NE, Saloustros IG and Vardas PE: Early cardiac gene transcript levels in peripheral blood mononuclear cells reflect severity in stable coronary artery disease. Hellenic J Cardiol 55: 119-125, 2014.

43. Durocher D, Charron F, Warren R, Schwartz RJ and Nemer M: The cardiac transcription factors $\mathrm{Nk} \times 2-5$ and GATA-4 are mutual cofactors. EMBO J 16: 5687-5696, 1997.

44. Hasegawa K, Lee SJ, Jobe SM, Markham BE and Kitsis RN: cis-Acting sequences that mediate induction of beta-myosin heavy chain gene expression during left ventricular hypertrophy due to aortic constriction. Circulation 96: 3943-3953, 1997.

45. Huang WY, Cukerman E and Liew CC: Identification of a GATA motif in the cardiac alpha-myosin heavy-chain-encoding gene and isolation of a human GATA-4 cDNA. Gene 155: 219-223, 1995.

46. Molkentin JD, Kalvakolanu DV and Markham BE: Transcription factor GATA-4 regulates cardiac muscle-specific expression of the alpha-myosin heavy-chain gene. Mol Cell Biol 14: 4947-4957, 1994.

47. Linhares VL, Almeida NA, Menezes DC, Elliott DA Lai D, Beyer EC, Campos de Carvalho AC and Costa MW: Transcriptional regulation of the murine Connexin40 promoter by cardiac factors Nkx2-5, GATA4 and Tbx5. Cardiovasc Res 64: 402-411, 2004.

48. Gallagher JM, Yamak A, Kirilenko P, Black S, Bochtler M Lefebvre C, Nemer M and Latinkić BV: Carboxy terminus of GATA4 transcription factor is required for its cardiogenic activity and interaction with CDK4. Mech Dev 134: 31-41, 2014

49. Rojas A, Kong SW, Agarwal P, Gilliss B, Pu WT and Black BL: GATA4 is a direct transcriptional activator of cyclin D2 and Cdk4 and is required for cardiomyocyte proliferation in anterior heart field-derived myocardium. Mol Cell Biol 28: 5420-5431, 2008.

50. Yamak A, Latinkic BV, Dali R, Temsah R and Nemer M Cyclin D2 is a GATA4 cofactor in cardiogenesis. Proc Natl Acad Sci USA 111: 1415-1420, 2014.

51. Lee Y, Shioi T, Kasahara H, Jobe SM, Wiese RJ, Markham BE and Izumo S: The cardiac tissue-restricted homeobox protein Csx/Nkx2.5 physically associates with the zinc finger protein GATA4 and cooperatively activates atrial natriuretic factor gene expression. Mol Cell Biol 18: 3120-3129, 1998.

52. Brown CO III, Chi X, Garcia-Gras E, Shirai M, Feng XH and Schwartz RJ: The cardiac determination factor, Nkx2-5, is activated by mutual cofactors GATA- 4 and Smad1/4 via a nove upstream enhancer. J Biol Chem 279: 10659-10669, 2004.

53. Laforest B and Nemer M: GATA5 interacts with GATA4 and GATA6 in outflow tract development. Dev Biol 358: 368-378, 2011.
54. Ang YS, Rivas RN, Ribeiro AJS, Srivas R, Rivera J, Stone NR, Pratt K, Mohamed TMA, Fu JD, Spencer CI, et al: Disease model of GATA4 mutation reveals transcription factor cooperativity in human cardiogenesis. Cell 167: 1734-1749.e22, 2016.

55. Maitra M, Schluterman MK, Nichols HA, Richardson JA, Lo CW, Srivastava D and Garg V: Interaction of Gata4 and Gata6 with Tbx5 is critical for normal cardiac development. Dev Biol 326: 368-377, 2009.

56. Luna-Zurita L, Stirnimann CU, Glatt S, Kaynak BL, Thomas S, Baudin F, Samee MA, He D, Small EM, Mileikovsky M, et al: Complex interdependence regulates heterotypic transcription factor distribution and coordinates cardiogenesis. Cell 164: 999-1014, 2016

57. Dai YS, Cserjesi P, Markham BE and Molkentin JD: The transcription factors GATA4 and dHAND physically interact to synergistically activate cardiac gene expression through a p300-dependent mechanism. J Biol Chem 277: 24390-24398, 2002.

58. Dai YS and Markham BE: p300 Functions as a coactivator of transcription factor GATA-4. J Biol Chem 276: 37178-37185, 2001.

59. Zhang X, Wang X, Zhu H, Zhu C, Wang Y, Pu WT, Jegga AG and Fan GC: Synergistic effects of the GATA-4-mediated miR-144/451 cluster in protection against simulated ischemia/reperfusion-induced cardiomyocyte death. J Mol Cell Cardiol 49: 841-850, 2010.

60. Glenn DJ, Rahmutula D, Nishimoto M, Liang F and Gardner DG: Atrial natriuretic peptide suppresses endothelin gene expression and proliferation in cardiac fibroblasts through a GATA4-dependent mechanism. Cardiovasc Res 84: 209-217, 2009.

61. Molkentin JD, Lu JR, Antos CL, Markham B, Richardson J, Robbins J, Grant SR and Olson EN: A calcineurin-dependent transcriptional pathway for cardiac hypertrophy. Cell 93: 215-228, 1998

62. Morimoto T, Hasegawa K, Wada H, Kakita T, Kaburagi S, Yanazume T and Sasayama S: Calcineurin-GATA4 pathway is involved in beta-adrenergic agonist-responsive endothelin-1 transcription in cardiac myocytes. J Biol Chem 276: 34983-34989, 2001.

63. Morin S, Charron F, Robitaille L and Nemer M: GATA-dependent recruitment of MEF2 proteins to target promoters. EMBO J 19: 2046-2055, 2000.

64. Kolettis TM, Barton M, Langleben D and Matsumura Y: Endothelin in coronary artery disease and myocardial infarction. Cardiol Rev 21: 249-256, 2013. 